\title{
WORK-RELATED THUMB PAIN AND ASSOCIATED RISK FACTORS AMONG MANUAL PHYSIOTHERAPISTS
}

\author{
Anam Akram ${ }^{\prime \otimes}$, Faiza Sharif', Ashfaq Ahmed'
}

\section{ABSTRACT}

OBJECTIVE: To find out the number of work-related thumb pain, its associated risk factors and treatment preferences among manual physiotherapists.

METHODS: This cross-sectional study used a modified self-administered questionnaire among manual physiotherapists in the government and private hospitals of Lahore, Pakistan. Sixty physiotherapists were recruited using simple consecutive sampling. Data was analyzed through SPPS v.2 I.0.

RESULTS: Out of 60 physiotherapists, $35(58.3 \%)$ were males. Majority $(n=43$; $71.6 \%)$ had age $<30$ years. Thirty-seven $(61.7 \%)$ participants had work experience of $\mathrm{I}-5$ years and $16.7 \%(n=10 / 60)$ worked for $>45$ hours per week. Out of $33(55 \%)$ physiotherapists with work-related painful thumbs, $75.8 \%$ $(n=25 / 33)$ had work experience of I-5 years and $24.24 \%(n=8 / 33)$ worked for $>45$ hours per week. About $55 \%(n=33 / 60)$ of all physiotherapists and $52 \%$ $(n=17 / 33)$ of those with painful thumbs had no preventive information. Handposition B was common in all physiotherapists $(n=36 / 60 ; 60 \%)$ and in those with painful thumb $(n=21 / 33: 64 \%)$. Almost $97 \%(n=32 / 33)$ of physiotherapists with painful thumb were right-handed. Interphalangeal joint was the most affected joint $(n=10 / 33 ; 30.3 \%)$ and affected thumb was dominant in nature with $84.8 \%$ $(n=28 / 33)$ cases. Trigger point therapy $(n=7 ; 11.7 \%)$ was a major cause to provoke symptoms. Stabilization exercise was found to be most satisfying treatment $(n=6 / 9 ; 66.67 \%)$.

CONCLUSION: A high percentage of work-related thumb pain was recorded among the manual physiotherapists of Lahore. Most of them suffer from workrelated pain due to the execution of manual therapy techniques, while stabilization exercise is the most satisfied therapy for thumb pain among them.

KEY WORDS: Musculoskeletal Diseases (MeSH); Physical Therapy Specialty (MeSH); Risk Factors (MeSH); Musculoskeletal Manipulations (MeSH); Thumb pain (Non-MeSH).

THIS ARTICLE MAY BE CITED AS: Akram A, Sharif F, Ahmed A. Workrelated thumb pain and associated risk factors among manual physiotherapists. Khyber Med Univ J 2020;12(2):149-53. DOI: 10.35845/kmuj.2020.19629.

\section{INTRODUCTION}

$P$ hysiotherapy is a health care profession mainly worried about the amendatory of impairments with disabilities and the upgradation of mobility, functional capability, the standard of life and movement possible through assessment, diagnosis, and physical interventions. The work environment remarkably contributes to work-related illnesses partly caused by conflicting or aggravated working circumstances, accelerated or worsened by workplace exposure stated by World Health Organization (WHO). ${ }^{1,2}$ Among physiotherapists, all structures within the thumb joints of a hand are most susceptible to biomechanical and job-related injuries
I. University Institute of Physical Therapy, Faculty of Allied Health Sciences, The University of Lahore, Lahore, Pakistan. Email凶: anamakram43@hotmail.com Contact \#: +92-333-845391।

Date Submitted: August 22, 2019 Date Revised: March 22, 2020

Date Accepted: March 25, 2020

due to manual therapy techniques that recurrently compress the thumb joint. ${ }^{3}$ The first metacarpophalangeal (MCP), and the carpometacarpal (CMC) joints are the most frequent areas of thumb pain among manual physiotherapists. ${ }^{4}$ The most important functional element of muscle framework is the setting of muscle fibers associated to the axis of pressure generation. $^{5}$

Physical therapy is most physically demanding profession because of this physiotherapists are more prone to develop work-related musculoskeletal problems. ${ }^{6,7}$ The musculoskeletal conditions are treated by manual techniques to get the good outcome so while treating the patients with manual techniques thumb is involved and due to ligamentous laxity of thumb, manual physiotherapists are more prone to develop thumb pain and hypermobility of joints of hand. ${ }^{8}$

Wajon, et al. concluded in their research that $83 \%$ physiotherapists while treating patients with manual therapy techniques, $87 \%$ unilateral and $85 \%$ posterio-anterior (PA) glide suffered from thumb pain. ${ }^{8}$ Work-related thumb pain is the second most common problem observed among manual physiotherapists after low back pain.' The inappropriate use of thumb while treating the patients of musculoskeletal conditions with manual therapy techniques result in thumb pain. ${ }^{10}$

Tobias JH, et al. showed that physiotherapists practicing manual and other techniques were suffering from more musculoskeletal conditions. ${ }^{10}$ They reported in their study that after low back pain, the second most common problem among physiotherapists was thumb pain. ${ }^{10}$ In the work settings of physiotherapists 
TABLE I: SOCIO-DEMOGRAPHIC CHARACTERISTICS OF PARTICIPANTS

\begin{tabular}{|c|c|c|c|}
\hline \multicolumn{2}{|c|}{ Characteristics } & \multirow{2}{*}{$\begin{array}{c}\begin{array}{c}\text { All participants } \\
\text { Number (\%) } \\
\mathbf{n}=60\end{array} \\
35(58.3 \%) \\
\end{array}$} & \multirow{2}{*}{$\begin{array}{c}\text { Work-related painful } \\
\text { thumb Number } \\
(\%) n=33\end{array}$} \\
\hline & Males & & \\
\hline Gender & Females & $25(41.47 \%)$ & $16(48.5 \%)$ \\
\hline \multirow{3}{*}{ Age (Years) } & $<30$ & $43(71.6 \%)$ & $29(87.9 \%)$ \\
\hline & $31-40$ & $15(25 \%)$ & $3(9.1 \%)$ \\
\hline & $4 I-50$ & $2(3.3 \%)$ & I (3.0\%) \\
\hline \multirow{6}{*}{ Work-experience } & $\mathrm{I}-5$ & $37(61.7 \%)$ & $25(75.8 \%)$ \\
\hline & $6-10$ & $12(20 \%)$ & $6(18.1 \%)$ \\
\hline & $11-15$ & $8(13.3 \%)$ & I (3.0\%) \\
\hline & $16-20$ & $\mathrm{I}(\mathrm{I} .7 \%)$ & $0(0 \%)$ \\
\hline & $21-25$ & I (I.7\%) & $0(0 \%)$ \\
\hline & $26-30$ & $\mathrm{I}(\mathrm{I} .7 \%)$ & I (3.0\%) \\
\hline \multirow{5}{*}{ Worked hours a week } & $<15$ & $27(45 \%)$ & $\mathrm{II}(33 \%)$ \\
\hline & $16-25$ & $6(10 \%)$ & $4(12 \%)$ \\
\hline & $26-35$ & $5(8.3 \%)$ & $4(12 \%)$ \\
\hline & $36-45$ & $12(20 \%)$ & $6(18 \%)$ \\
\hline & $>45$ & $10(16.7 \%)$ & $8(24 \%)$ \\
\hline \multirow{2}{*}{ Preventive Information } & Yes & $27(45 \%)$ & $16(48 \%)$ \\
\hline & No & $33(55 \%)$ & $17(52 \%)$ \\
\hline \multirow{3}{*}{ Hand Position } & Position A & II (I8.3\%) & $6(18 \%)$ \\
\hline & Position B & $36(60 \%)$ & $21(64 \%)$ \\
\hline & Position C & $13(21.7 \%)$ & $6(18 \%)$ \\
\hline \multirow{2}{*}{ Dominant hand } & Right handed & $55(91.7 \%)$ & $32(97 \%)$ \\
\hline & Left handed & $5(8.3 \%)$ & $\mathrm{I}(3.0 \%)$ \\
\hline
\end{tabular}

TABLE II: LOCATION OF PAIN IN STUDY PARTICIPANTS ( $\mathbf{N}=33)$

\begin{tabular}{|l|l|c|c|}
\hline \multicolumn{2}{|c|}{ Affected Location } & Frequency & Percentage \\
\hline \multirow{4}{*}{ Affected Joint } & IP,MP,CMC & 9 & 27.2 \\
\cline { 2 - 4 } & IP and MP & 2 & 6.1 \\
\cline { 2 - 4 } & IP and CMC & 7 & 21.2 \\
\cline { 2 - 4 } & MP and CMC & 2 & 6.1 \\
\cline { 2 - 4 } & IP & 10 & 30.3 \\
\cline { 2 - 4 } & MP & 1 & 3 \\
\cline { 2 - 4 } & CMC & 2 & 6.1 \\
\hline \multirow{3}{*}{ Affected Thumb } & Non-dominant thumb & 2 & 6.1 \\
\cline { 2 - 4 } & Dominant thumb & 28 & 84.8 \\
\cline { 2 - 4 } & Both thumbs & 3 & 9.1 \\
\hline
\end{tabular}

IP $=$ Interphalangeal; $M P=$ Metacarpophalangeal; $C M C=$ arpometacarpal

due to the nature of their profession and work schedule, they are more susceptible to musculoskeletal injuries. ${ }^{11,12}$ The lifetime commonness of work-related thumb problem in the physiotherapists was $65.3 \%$ reported by Heather Jenkins, et al. in their study. ${ }^{13}$ Baren, et al. reported that lifetime commonness of work-related thumb pain ranges from $62.5 \%$ to $83 \%$ researches were concentrated on thumb and wrist problems. ${ }^{3}$
The one-year occurrence rate was $20.7 \%$ for the job-related musculoskeletal injuries was reported by Campo, et al. ${ }^{14}$ The physical therapy procedures that increase the physical job stress were twisting, bending postures, soft tissue mobilization and other manual strategies. The occurrence of job-related musculoskeletal injuries associated with an extensive use of manual techniques appears to be greater reported by
Darragh AR and Grooten WJA et al. in their study. ${ }^{15,16}$ The study by Hu MT, et al. highlighted the need to undertake comprehensive studies of physical therapist's work-related wrists/hand area complaints. ${ }^{17}$ Different former studies have indicated thumb pain in the range of $11.1 \%$ to $83 \%{ }^{17}$ Rossettini G, et al. indicated in their study findings of physiotherapists in which they carefully inspected hand region concerns with respect to thumb pain, the documented I year incidence ranges from $11.1 \%$ to $83 \% .^{18}$ This proportion seems to be greater when it comes to the comprehensive use of manual techniques. $^{18}$

Physiotherapists play a vital role in society. They use manual techniques and therapeutic exercises to relieve their patient's pain, impairments and functional limitations. There are known benefits of this research to find how long the work-related thumb pain is c o m mon among manual physiotherapists so they follow some protective measures to protect themselves and their career from workrelated thumb pain.

The aim of this study was to determine the prevalence of work-related thumb pain and the risk factors that contribute in thumb pain among manual physiotherapists of Lahore, Pakistan and their preferences to treat them.

\section{METHODS}

This study cross-sectional, analytical study design was permitted and ethically approved via Institutional Review Board of University Institute of Physical Therapy, Faculty of Allied Health Sciences, The University of Lahore (UOL), Lahore, Pakistan. The study used a non-probability convenient sampling technique and 60 physiotherapists were enrolled after taking informed written consent and was conducted from April 2018 to September 2018. The sample size was calculated by using the formula $n=\frac{z^{2} 1-\frac{\alpha}{s} p(1-p)}{e^{2}}$ in which the confidence interval $(\mathrm{Cl})$ was $90 \%$, absolute precision $(\mathrm{d}=0 . \mathrm{II})$ and anticipated population proportion was 0.44 $(p=0.44)$. The data was collected from 
TABLE III: MANUAL TECHNIQUES PROVOKING/ AGGRAVATING SYMPTOMS IN STUDY PARTICIPANTS

\begin{tabular}{|l|c|}
\hline \multicolumn{1}{|c|}{ Symptoms provoked } & $\begin{array}{c}\text { \% of total with } \\
\text { affected thumb } \\
(\mathbf{n = 3 3 )}\end{array}$ \\
\hline Soft tissue mobilization & $2(6.1 \%)$ \\
\hline Manipulation & $3(9.1 \%)$ \\
\hline Trigger point therapy & $7(21.2 \%)$ \\
\hline Mobilizations & $\mathrm{I}(3 \%)$ \\
\hline Soft tissue mobilization + trigger point therapy+mobilizations & $5(15.2 \%)$ \\
\hline Manipulation + trigger point therapy & $\mathrm{I}(3 \%)$ \\
\hline Manipulation + trigger point therapy+mobilizations & $2(6.1 \%)$ \\
\hline Trigger point therapy+mobilizations & $2(6.1 \%)$ \\
\hline Soft tissue mobilization+manipulation+ mobilizations & $2(6.1 \%)$ \\
\hline Soft tissue mobilization+trigger point therapy & $2(6.1 \%)$ \\
\hline Soft tissue mobilization+mobilizations & $3(9.1 \%)$ \\
\hline Manipulation + mobilizations & $3(9.1 \%)$ \\
\hline
\end{tabular}

TABLE IV: TREATMENT AND LEVEL OF SATISFACTION AMONG STUDY PARTICIPANTS

\begin{tabular}{|c|c|c|c|c|c|}
\hline Treatments & Satisfied & $\begin{array}{c}\text { Very } \\
\text { satisfied }\end{array}$ & Neutral & $\begin{array}{c}\text { Participants } \\
\text { tried } \\
\text { treatment } \\
\quad(n=33)\end{array}$ & $\begin{array}{l}\% \text { of total } \\
\text { with } \\
\text { affected } \\
\text { thumb }\end{array}$ \\
\hline Taping & $6(46.15 \%)$ & $5(38.46 \%)$ & $2(15.39 \%)$ & 13 & $39.3 \%$ \\
\hline Medication & $0(0 \%)$ & $0(0 \%)$ & $3(100 \%)$ & 3 & $9.1 \%$ \\
\hline Rest & $9(32.13 \%)$ & $12(42.87 \%)$ & $7(25 \%)$ & 28 & $84.8 \%$ \\
\hline Stabilization exercises & $6(66.67 \%)$ & $\mathrm{I}(\mathrm{I} . \mathrm{I} \mathrm{I} \%)$ & $2(22.22)$ & 9 & $27.3 \%$ \\
\hline Medical intervention & $0(0 \%)$ & $0(0 \%)$ & $0(0 \%)$ & 0 & $0 \%$ \\
\hline Brace & $2(50 \%)$ & I (25\%) & I (25) & 4 & $12.1 \%$ \\
\hline
\end{tabular}

The University of Lahore Teaching Hospital, University Physical Therapy and Rehabilitation Clinic, UOL, The Pakistan Society for The Rehabilitation of Disabled, Mayo Hospital, Rehab cure, Shaikh Zayed Hospital, Ittefaq Hospital Lahore. The study included both male and female physiotherapist who were having at least I year of work experience as a manual physiotherapist and were using manual therapy techniques while treating patients in government and private hospitals of Lahore. This study excluded those physiotherapists who were just teaching theoretically not training the students for manual techniques at academic side, had rheumatic disease and any past medical or surgical history of forearm or the wrist disease. Majority of physiotherapists $(60 \%)$ tried the position of hands (spinal manipulative therapy technique of Central postero- anterior (PA) glides using thumb pressure) in which thumbs were coming across each other, MCP joints remained untouched and index fingers remained unsupported by the thumbs. " The study used a modified self- administered questionnaire, which was distributed manually among the manual physiotherapists. "If the thumb pain was present then they were asked to fill the further questions that were related about the dominant hand, joint affected, techniques that aggravated their symptoms, consequences and treatments they tried according to their satisfaction. SPPS (Software Statistical Package For Social Science $\left.{ }^{\circledR}\right)$ v 21.0 was used as statistical tool. Mean and standard deviation were calculated for quantitative variables while qualitative variables were presented in the form of frequency and percentage. To indicate an association between variables,
Fisher-Exact test was performed, pvalue $<0.05$ was taken as significant.

\section{RESULTS}

Out of 60 physiotherapists, 35 (58.3\%) were males while $25(41.47 \%)$ were females. In age group, majority had age < $30(n=43 ; 71.6 \%)$, followed by age group of $3 \mid-40$ years $(n=15 ; 25 \%)$. Thirty-seven (61.7\%) participants had work experience of $\mathrm{I}-5$ years and $16.7 \%$ $(n=10 / 60)$ worked for $>45$ hours per week. Rest details of other demographic variables are illustrated in Table I.

Out of total 60,33 (55\%) physiotherapist indicated that they suffered from thumb pain once in their career, 25 (4I.7\%) had thumb pain at the time of survey and 27 (45\%) participants never suffered from thumb pain in their career. The most common affected joint was interphalangeal joint (IP) $(n=10 / 33$. $30.30 \%$ ), followed by involvement of all the joints interphalangeal joint (IP), metacarpophalangeal joint (MP), and carpometacarpal joint (CMC) in a single person $(n=9 / 33 ; 27.27 \%)$ [Table II] and a significant association was recorded between thumb pain and joints hurting $(\mathrm{P}$ value $=0.00 \mathrm{I})$. In affected thumb, dominant thumb was affected the most $(\mathrm{n}=28 / 33 ; 85 \%)$ [Table II] and a significant association of thumb pain was recorded with dominant thumb hurting ( $P$ value $=0.00 \mathrm{I}$ ).

The participants reported that their thumb pain was aggravated/provoked by trigger point therapy 7 (21.2\%), collectively soft tissue mobilization, trigger point therapy, and mobilizations 5 (I5.2\%) [Table III] and a significant association of thumb pain to manual techniques that aggravated their symptoms $(P$-value $=0.00 \mathrm{I})$.

This study showed that manual physiotherapists were mostly satisfied by stabilization exercises $(n=6 / 9 ; 66.67 \%)$ and a significant association was noted $(\mathrm{P}$ value $=0.00 \mathrm{I})[$ Table IV $]$.

\section{DISCUSSION}

This research revealed that $41.7 \%$ of the physiotherapists suffered from thumb pain when they were asked to fill out the survey, $55 \%$ suffered from thumb pain once in their career. There were $25 / 33$ (75.8\%) participants in between I-5 years of work experience and 29 (87.9\%) participants $<30$ years of age suffered 
from thumb pain. The II (33\%) participants who used to work for less than 15 hours in a week suffered from thumb pain, $21(64 \%)$ participants who used position $B$ (spinal manipulative therapy technique of Central posteroanterior (PA) glides using thumb pressure) during their practice suffered from thumb pain, 32(97\%) participants used right hand as a dominant hand and felt thumb pain. Mostly affected joints $9(27.2 \%)$ in thumb were interphalangeal, metacarpophalangeal and carpometacarpal joints while the main aggravating technique was $7(21 \%)$ trigger point therapy.

The results of this study in which $41.7 \%$ of physiotherapists suffered from thumb pain at that moment and $55 \%$ once in their career was similar to the study reported by Van de Velde, et al. in which $41 \%$ physiotherapist suffered from thumb pain at the same moment and $65 \%$ complaint about having thumb pain once in their carrer." The 25 (75.8\%) participants in between I-5 year of work experience suffered from thumb pain these results are similar to the one of the study in which it was revealed that the incidence and severity was high during the first five years of clinical practice due to inexperience. ${ }^{19}$ This study revealed that $29(87.9 \%)$ participants of $<30$ years suffered from thumb pain similar to the results of another study in which they analyzed and explored that the work-related thumb pain was common among the newly qualified physiotherapists of the age group $<30$ years. It could be due to the incorrect placement of the thumb and failure to stabilize their thumb during the utilization of manual practices and increased burden of work. ${ }^{20}$ The average score of thumb pain on Numeric Pain Reading Scale was $2 / 10$ in our study comparable with the past study of Wajon, et al. study in which the average score of thumb pain was given $4.2 / 10.2$ I We failed to embody the idea of pain in our study, so it's not clear whether or not the physiotherapists complained concerning pain, stiffness or fatigue of the thumb.

Our study revealed that 32 (97\%) suffered from thumb pain in dominant hand whereas One study reported that $33 \%$ suffered thumb pain in dominant hand. ${ }^{7}$ Another study concluded that carpometacarpal joint of dominant hand is more prone to thumb related problems but in our study physiotherapists interphalangeal joint of dominant thumb
(30.3\%) was most painful joint while carpometacarpal joint of dominant thumb was painful in only $(6.1 \%){ }^{22}$ In our study we found trigger point therapy $(21 \%)$, mobilization (3\%) and manipulation (9\%) alone to cause thumb pain among manual physiotherapists whereas another study concluded that $50 \%$ physiotherapists suffered from thumb pain due to the mobilization and manipulation techniques. $^{23}$

In our study, we didn't find any significant association between thumb pain and gender but one study reported that females were 2.6 times more prone to develop thumb pain in their career than males. ${ }^{18}$ The difference in results from study to study could be due to different samples. Our study revealed that workrelated thumb pain was more common among males $(51.5 \%)$ as compared to females (48.5\%) while on the other hand, the study by Areesa Yaseen, et al. concluded that females $(25 \%)$ were more affected with work-related thumb pain as compared to males (23\%). ${ }^{7}$ The former studies explored that experienced physiotherapists were not more prone to develop thumb pain due to the trained skills. This finding is in accordance with past examination that has furthermore realized that manual therapists are at higher danger of emerging issues like thumb pain. ${ }^{24}$ In our study we find a significant association between thumb pain and manual therapy techniques comprising of soft tissue mobilization, trigger point therapy, manipulations and mobilizations similar results were indicated in one of the study in which a high proportion of thumb pain was found among physiotherapists and physiotherapists thought that their thumb pain was due to the consequences of manual therapy techniques comprises of soft tissue mobilization, trigger point therapy, and manipulations. ${ }^{25}$

The sample size was too small, data was collected from limited physiotherapists in a limited time and convenient sampling technique was used so the results may lack in generalizability. The study was based on interviews taken from physiotherapists so there may be some wrongly filled questions because of forgetfulness or negligence.

\section{CONCLUSION}

A high percentage of work-related thumb pain was recorded among the manual physiotherapists of Lahore. Most of them suffer from work-related pain due to the execution of manual therapy techniques, while stabilization exercise is the most satisfied therapy for thumb pain among them.

\section{REFERENCES}

I. World Health Organization (WHO). Identification and control of workrelated diseases: report of a WHO expert committee [meeting held in Geneva from 28 November to 2 December 1983]: World Health Organization; 1985. [Accessed on: August I2, 2019]. Available from URL: h t t ps: / / a p ps. who.int / iris/handle/I0665/40I76.

2. Milhem M, Kalichman L, Ezra D, Alperovitch-Najenson D. Workrelated musculoskeletal disorders among physical therapists: A comprehensive narrative review. Int ] Occup Med Environ Health 20I6;29(5):735-47. DOI: 10.13075 /ijomeh. 1896.00620.

3. Barnes R, Colyn H, Moolman C, Roux $Z$, Shabort D, Yzel M, et al. The lifetime prevalence of work-related thumb and wrist pain among physiotherapists in Bloemfontein. Occup Health South Africa 201।;17(4):16-22.

4. Hu MT, Hsu AT, Lin SW, Su FC. Effect of general flexibility on thumb-tip force generation - implication for mobilization and manipulation. Man Ther 2009; I 4(5):490-5. DOI: 10.1016/j.math.2008.10.003

5. Gupta S, Michelsen-Jost H. Anatomy and function of the thenar muscles. Hand Clin. 2012;28(I):I-7. DOI: 10.1016/j.hcl.2011.09.006.

6. Muruganantham B, Nayak B, Dave D, Kotia P. Work related musculoskeletal disorders among Indian physiotherapists. Physiother 2015 May I;IOI(I):el059-60. DOI: 10.1016/j.physio.2015.03.1941

7. Yaseen A, Yaseen H, Yaseen A. Work related thumb pain, its prevalence, risk factors and prevention among physical therapists. Int J Endorsing Health Sci Res 2019;7(I).I-7. DOI: 10.29052/JJEHSR.v7.il.2019.0I-10

8. Wajon A, Ada L. Prevalence of thumb pain in physical therapists practicing spinal manipulative therapy. J Hand Ther 2003;16(3): 237-44. DOI: 


\section{I0.1016/s0894-II30(03)00039-5.}

9. Mubeen M, Ans M, Ayaz S, Mohiuddin E, Tufail A, Mubeen F, et al. The Frequency of Thumb Pain Among Physiotherapists Practicing Spinal Manual Therapy in Lahore, Pakistan. PakJ Med Biol Sci 20 I 8;2( I):27-3I.

10. Tobias JH, Deere K, Palmer S, Clark $\mathrm{EM}$, Clinch J. Joint hypermobility is a risk factor for musculoskeletal pain during adolescence: findings of a prospective cohort study. Arthritis Rheum 2013;65(4):II07-I5. DOI: 10.1002/art.37836

II. Van de Velde K, Cattrysse E. Workrelated thumb pain in physiotherapists: Prevalence, risk factors and prevention, an observational study. Int J Physiother 20। 3;3(4): 145-53.

12. Darragh AR, Huddleston W, King P. Work-related musculoskeletal injuries and disorders among occupational and physical therapists. Am J Occup Ther 2009;63(3):35I-62. DOI: 10.50 I4/ajot.63.3.35I.

13. Jenkins $H$, Myezwa $H$. Work-related thumb disorders in South African physiotherapists treating musculoskeletal conditions using manual therapy techniques. S Afr J Physiother 20I5;7I(I):249. DOI: I0.4I02/sajp.v7lil.249.

14. Campo M, Weiser S, Koenig KL, Nordin M. Work-related musculoskeletal disorders in physical therapists: a prospective cohort study with I-year follow-up. Phys Ther 2008;88(5):608-I9. DOI: I0.2522/ptj.20070I 27

15. Darragh AR, Campo M, King P. Workrelated activities associated with injury in occupational and physical therapists. Work 20I2;42(3):373-84. DOI: 10.3233/WOR-20I2-I430

16. Grooten WJA, Wernstedt P, Campo M. Work-related musculoskeletal disorders in female Swedish physical therapists with more than 15 years of job experience: prevalence and associations with work exposures. Physiother Theory Pract 201I; 27(3):213-22. DOI: 10.3109/ 09593985.2010 .481323

17. Hu MT, Su FC, Hsu AT. Effect of prior experience and task stability on the intrinsic muscle activity of the thumb. Man Ther 20I4;19(5):484-9. DOI: 10.1016/j.math.2014.05.003

18. Rossettini G, Rondoni A, Schiavetti I, Tezza S, Testa M. Prevalence and risk factors of thumb pain in Italian manual therapists: An observational crosssectional study. Work 2016;54(I):159-69. DOI: 10.3233/ WOR-162289

19. Walkeden S, Walker KM. Perceptions of physiotherapists about their role in health promotion at an acute hospital: a qualitative study. Physiotherapy 20I5;10I(2): 226-3I. DOI: 10.1016/ j.physio. 20।4.06.005
20. Walsh T, Delahunt E, McCarthy Persson U. Effects of taping on thumb alignment and force application during PA mobilisations. Man Ther 20II;I6(3):264-9. DOI: 10.1016/j.math.2010.11.006.

2I. Wajon A, Ada L, Refshauge K. Workrelated thumb pain in physiotherapists is associated with thumb alignment during performance of PA pressures. Man Ther 2007; I2(I): 12-6. DOI: 10.1016/j.math.2005.09.003

22. Snodgrass SJ, Rivett DA, Chiarelli P, Bates AM, Rowe LJ. Factors related to thumb pain in physiotherapists. Aust J Physiother 2003;49(4):243-50. DOI: 10.1016/s0004-95 I4 (I4)60140-9.

23. Dsouza S, Mathew A, KU DK. Work related musculoskeletal disorders in physiotherapist; prevalence and associated factors: A review of literature. Int J Health Sci Educ 20|6;6(6).344-5|

24. Anyfantis ID, Biska A. Musculoskeletal disorders among greek physiotherapists: traditional and emerging risk factors. Saf Health Work 20I8;9(3):314-8. DOI: 10.1016/j.shaw.2017.09.003.

25. McLeod GA, Murphy M, Dlabik B. Work-related musculoskeletal injuries among Australian osteopaths: A preliminary investigation. International J Osteopath Med 20।8;27(20|8):|4-22. DOI: 10.1016/j.ijosm.2017. 11.003 .

\section{AUTHORS' CONTRIBUTIONS}

Following authors have made substantial contributions to the manuscript as under:

AA: Conception, acquisition, analysis and interpretation of data, drafting the manuscript, final approval of the version to be published.

FS \& AA: Study design, critical review, final approval of the version to be published.

Authors agree to be accountable for all aspects of the work in ensuring that questions related to the accuracy or integrity of any part of the work are appropriately investigated and resolved.

CONFLICT OF INTEREST
Authors declared no conflict of interest
GRANT SUPPORT AND FINANCIAL DISCLOSURE
NIL

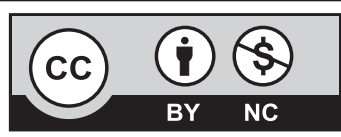

This is an Open Access article distributed under the terms of the Creative Commons Attribution-Non Commercial 2.0 Generic License. 